\title{
Unilaterally Disrupted Structural and Functional Connectivity of The Fronto-limbic System In Idiopathic Hypogonadotropic Hypogonadism
}

\section{Jibin Cao}

The First Affiliated Hospital of China Medical University

\section{Lingling Cui}

The First Affiliated Hospital of China Medical University

Zhiyang Yin

The First Affiliated Hospital of China Medical University

\section{Boyu Chen}

The First Affiliated Hospital of China Medical University

\section{Hu Liu}

The First Affiliated Hospital of China Medical University

\section{Miao Chang}

The First Affiliated Hospital of China Medical University

\section{Chao Li}

The First Affiliated Hospital of China Medical University

\section{Guoguang Fan ( $\nabla$ fanguog@sina.com )}

The First Affiliated Hospital of China Medical University

\section{Research}

Keywords: Idiopathic Hypogonadotropic Hypogonadism, Kallmann's syndrome, Olfactory cortex, Structural connectivity, Functional connectivity

Posted Date: August 27th, 2021

DOl: https://doi.org/10.21203/rs.3.rs-837648/v1

License: (c) (i) This work is licensed under a Creative Commons Attribution 4.0 International License. Read Full License 


\section{Abstract}

Background: Idiopathic hypogonadotropic hypogonadism $(\mathrm{IHH})$ is rare and can either be associated with normal or defective olfactory sensation, classified as normosmic $\mathrm{HH}(\mathrm{nIHH})$ or Kallmann's syndrome (KS), respectively. We do not yet understand the central processing pathways in the olfactory system, especially regarding these disorders. We aimed to compare the resting-state structural and functional connectivity (FC) of olfactory neural pathways in patients with $\mathrm{nIHH}$ and $\mathrm{KS}$.

Methods: A total of 50 males were studied: $13 \mathrm{nIHH}$ patients, $12 \mathrm{KS}$ patients, and 25 healthy controls (HCs). All subjects underwent diffusion tensor imaging (DTI) and functional magnetic resonance imaging (fMRI) scans. Structural and functional connectivity data analyses were then performed.

Results: The results indicated that fractional anisotropy (FA) was significantly decreased in the right uncinate fasciculus (UF) in the KS group. The olfactory cortex FC values of the right gyrus rectus and orbitofrontal cortex (OFC) in the KS group were decreased compared with those in the HC group and increased compared with those in the $\mathrm{nIHH}$ group $(\mathrm{nlHH}<\mathrm{KS}<\mathrm{HC}$ ). Moreover, there were significant negative correlations between right UF FA and olfactory cortex FC to both the gyrus rectus and OFC within the $\mathrm{nIHH}$ and $\mathrm{HC}$ groups.

Conclusion: We have reported significant structural and functional disruptions unilaterally at the right junction of the fronto-limbic system in KS patients. The results may indicate that a specific structuralfunctional asymmetry exists in the olfactory cortex pathways in KS patients.

\section{Introduction}

Idiopathic hypogonadotropic hypogonadism $(\mathrm{IHH})$ is a sporadic genetic disorder. The clinical features are total or partial lack of pubertal development and infertility due to complete or partial absence of gonadotropin-releasing hormone (GnRH)-mediated release of follicle-stimulating hormone (FSH) and luteinizing hormone $(\mathrm{LH})$ in individuals with otherwise normal anterior pituitary anatomy and function. $\mathrm{IHH}$ can either be associated with a normal or defective olfactory sensation, classified as normosmic $\mathrm{IHH}$ (nIHH, $40 \%$ ) or Kallmann's syndrome (KS, 60\%), respectively(1). Human embryo cytogenetic examination found that olfactory nerve fascicles were unable to penetrate the forebrain in KS patients; thus, the migration of $\mathrm{GnRH}$ neurons was blocked (2-5).

An increasing number of neuroimaging articles on the olfactory system have significantly contributed to the localization of the olfactory cortex. However, localization of the olfactory cortex has also presented significant challenges to the scientific community. Over the last 30 years, technological developments in neuroimaging have facilitated progress in particular (6-8). The structural alterations of the rhinencephalon in KS patients have been well confirmed through magnetic resonance (MR) imaging (9, 10). However, we do not yet fully understand the olfactory system processing pathways in IHH patients. There is still considerable discrepancy concerning the best way to study olfactory-mediated brain activity. 
Resting-state functional connectivity ( $\mathrm{rFC}$ ) reflects the interregional correlations in neuronal variability using blood oxygen level-dependent (BOLD) signal fluctuations (11). Diffusion tensor imaging (DTI) provides measurements to investigate the integrity of white matter architecture in vivo. Some human neuroimaging studies have combined rsFC and DTI to elucidate the functional and structural connectivity between brain regions and show neurobiological-related abnormalities $(12,13)$.

On this basis, we explored the olfactory neural pathways through both rsFC and DTI to examine the olfactory processing mechanism of $\mathrm{IHH}$ patients.

\section{Materials And Methods}

\section{Subjects and clinical evaluation}

Twenty-five patients ( $13 \mathrm{nIHH}$ patients and $12 \mathrm{KS}$ patients) with an average age of $17.88 \pm 1.51$ years, ranging from 15 to 21 years of age, were recruited from the Department of Endocrinology and were assessed. All patients were males. A complete laboratory endocrine examination was obtained for each patient. The Smell Identification Test was performed to evaluate olfactory function (14). Clinical symptoms and signs of hypogonadism, as well as data from clinical reports indicating normal or defective olfactory function, were used as the diagnostic criteria for KS or $\mathrm{nIHH}$.

A total of 25 age-matched healthy male controls were recruited from the community. MRI scans and laboratory tests were performed. Exclusion criteria for all participants in our control group included the following: (1) any history of prematurity and other endocrine diseases, (2) any psychiatric diseases or neurological disorders, (3) a history of neurosurgery or head trauma with a loss of consciousness $\geq 5$ min, (4) medication history that may affect the central nervous system, and (5) any MRI contraindications. This study was approved by the medical research ethics committee and was in accordance with the Declaration of Helsinki. All participants provided written informed consent.

\section{MRI acquisition}

We performed MRI scans by using a GE Signa HDX 3.0T MR scanner. Thin-section ( $1 \mathrm{~mm})$ coronal three-dimensional time of flight spoiled gradient recalled acquisition (3D T1 SPGR) and three-dimensional fast imaging employing steady-state acquisition (3D FIESTA) were acquired for rhinencephalon evaluation. At least 2 radiologists separately evaluated the olfactory sulci and bulbs of the 25 patients and 25 healthy controls. Functional magnetic resonance imaging ( $\mathrm{fMRI}$ ) scans were obtained using a spin-echo planar imaging sequence aligned to the anterior and posterior commissure plane (AC-PC plane) with the following scan parameters: echo time $(T E)=30 \mathrm{~ms}$, repetition time $(T R)=2000 \mathrm{~ms}$, matrix $=64 \times$ 64 , flip angle $=90^{\circ}$, field of view $(F O V)=240 \times 240 \mathrm{~mm}$, 35 slices of $3 \mathrm{~mm}$, and no gap. DTI was performed in alignment with the AC-PC plane using a spin-echo planar imaging sequence. We applied diffusion sensitizing gradients along 25 non-collinear directions ( $b$ value $=1000 \mathrm{~s} / \mathrm{mm}^{2}$ ), together with a non-diffusion weighted acquisition. The scan parameters were as follows: TE $=85.4 \mathrm{~ms}$, TR $=17000 \mathrm{~ms}$, 
matrix $=120 \times 120$, FOV $=240 \times 240 \mathrm{~mm}$, slice thickness $=2 \mathrm{~mm}$, no gap, and 65 slices.

The subjects were to close their eyes but remain awake throughout the scan.

\section{MRI data processing and analysis}

\section{FMRI data processing}

Resting-state fMRI data pre-processing included disposing the first 10 time points, slice timing, head motion correction, and normalization to the Montreal Neurological Institute (MNI) template (resampling voxel size $=3 \times 3 \times 3 \mathrm{~mm}^{3}$ ), followed by spatial smoothing (full width at half-maximum $=6 \mathrm{~mm}$ ). Subjects with excessive motion (head motion $>3 \mathrm{~mm}$ or head rotation $>3^{\circ}$ ) were excluded. Preprocessing of REST involves filtering the time series of each voxel (bandpass filtering, $0.01-0.08 \mathrm{~Hz}$ ) to reduce the effects of low-frequency drifts and high-frequency physiological noise. Linear regression was performed for the head motion parameters, white matter signal, cerebrospinal fluid signal, and global mean signal to eliminate the influence of the nuisance covariates.

\section{Definition of Regions of Interest (ROIs)}

We selected the bilateral olfactory cortex as the seed ROI based on the definition of the automated anatomical labelling ( $A A L$ ) template contained in DPABI (resampling voxel size $=3 \times 3 \times 3 \mathrm{~mm}^{3}$ ) (15). The olfactory cortex ROls were defined as bilateral regions placed on Brodmann's areas 21 and 22 in MNI coordinates using the WFU_PickAtlas (https://www.nitrc.org/frs/?group_id=46). The detailed olfactory cortex ROIs are provided in the Supplementary results (Fig. S1). A reference time series was extracted by averaging the $\mathrm{fMRI}$ time series of all of the voxels within the ROI in each participant. The correlations between the seed ROI and the rest of the brain were calculated in a voxel-wise manner by DPABI. The correlation coefficients were transformed to z-values using Fisher's r-to-z transformation.

\section{DTI data processing}

PANDA software was used to process the DTI Images (16) (Pipeline for Analysing braiN Diffusion imAges 1.2.3 http://www.nitrc.org/projects/panda/), which synthesizes procedures in FSL (http://fsl.fmrib.ox.ac.uk/fsl), MRIcron (http://www.mccauslandcenter.sc.edu/mricro/mricron), and Diffusion Toolkit (http://www.nmr.mgh.harvard.edu/ rpwang/dtk). The following steps were used to preprocess images: converting DICOM files into NIfTI images, estimating the brain mask, cropping images, correcting for the eddy-current effect, averaging acquisitions, calculating DTI metrics, and generating diffusion metrics for statistical analysis. The individual images of the diffusion metrics were transformed from native space to standard MNI space by spatial normalization (voxel size $=1 \times 1 \times 1 \mathrm{~mm}^{3}$ ).

\section{Statistical analysis}

The rsFC and fractional anisotropy (FA) results in the three groups were analysed by ANOVA using DPABI software. Multiple comparisons were performed by Gaussian random field (GRF) correction, and the significance threshold was set at $p<0.05$ at the cluster level and $p<0.01$ at the voxel level. Then, we 
performed post hoc pair-wise comparisons of olfactory cortex FC strength among groups (KS v. HC, $\mathrm{nIHH}$ v. $\mathrm{HC}$ and KS v. $\mathrm{HC})$ in significant regions with Bonferroni tests $(\mathrm{p}<0.05)$. The fine anatomical localization of statistical results was acquired based on the AAL template.

We performed Pearson's correlation analyses to investigate the correlations between the FA value and FC strength, showing significant differences among the three groups separately. Statistical Package for the Social Sciences (SPSS) software, version 20.0 (SPSS Inc., Chicago, IL, USA), was used to perform statistical analysis of clinical and demographical variables. All statistical thresholds were set at $\mathrm{p}<0.05$.

\section{Result}

\section{Demographic and clinical characteristics}

The demographic and clinical characteristics of the 25 patients (12 KS and $13 \mathrm{nIHH}$ patients), including age, handedness, the results of the olfactory acuity tests, and the MRI results for evaluating rhinencephalon, are all displayed in Table 1.

\section{Comparison of Olfactory cortex-FC changes among groups}

\section{KS patients vs. HCs}

Compared with the $\mathrm{FC}$ strengths of the $\mathrm{HC}$ group, the olfactory cortex $\mathrm{FC}$ strengths in the bilateral dorsolateral prefrontal cortex (DLPFC), gyri recti, orbitofrontal cortex (OFC), left middle temporal gyrus, angular gyrus, inferior parietal lobule, precentral gyrus, right postcentral gyrus and supramarginal gyrus were decreased in the KS group ( $P<0.05$, corrected) (Fig. 1, Table II,Fig.S2A).

\section{KS patients vs. $\mathrm{nlHH}$ patients}

Compared with the FC strengths of the $\mathrm{nIHH}$ group, the olfactory cortex FC strengths were decreased in the right supramarginal gyrus, left inferior parietal lobule, and precentral and postcentral gyrus and increased in the right gyrus rectus, postcentral gyrus, bilateral DLPFC, and OFC in the KS group $(P<0.05$, corrected) (Fig. 1, Table Il, Fig.S2B).

\section{nIHH patients vs. HCs}

Compared with the FC strengths in the $\mathrm{HC}$ group, the olfactory cortex $\mathrm{FC}$ strengths were decreased in the bilateral gyri recti, OFC, DLPFC, left inferior parietal lobule, middle temporal gyrus, supramarginal gyrus, angular gyrus, precentral gyrus, and right postcentral gyrus and increased in the left postcentral gyrus in the $\mathrm{nIHH}$ group $(P<0.05$, corrected) (shown in Fig. 1, Table II, Fig.S2C).

\section{Anatomical connectivity damage among groups}

Compared with the $\mathrm{HC}$ and $\mathrm{nIHH}$ groups, the FA value in the right uncinate fasciculus (UF) decreased significantly in the KS group $(P<0.05$, corrected) (Fig. 2$)$. 


\section{Correlation analyses}

There were significant negative correlations between right UF FA values and olfactory cortex FC to both the gyrus rectus and OFC within the $\mathrm{nIHH}$ and $\mathrm{HC}$ groups $(r=-0.437 ; P=0.03 ; r=-0.682 ; P=0.01)$. However, there was no significant correlation within the KS group ( $P>0.05)$ (shown in Fig. 3).

\section{Discussion}

To our knowledge, we are the first researchers to compare the structural and functional connectivity of olfactory cortex neural pathways in patients with $\mathrm{nIHH}$ and KS by combining DTI and rsFC to identify biomarkers for the identification of two diseases. We have reported significant structural and functional disruption unilaterally at the right junction of the fronto-limbic system in KS patients. The results may indicate that a specific structural-functional asymmetry exists in the olfactory cortex pathways in KS patients.

Our results revealed that the olfactory cortex FC values of the bilateral gyri recti and OFC, which were close to the olfactory bulbs and symmetrically clustered in the frontal basal regions, changed in both the $\mathrm{KS}$ and $\mathrm{nIHH}$ groups. The OFC, which is the key region of the olfactory system, is considered to be not only deeply involved in olfactory processing, such as odour recognition and olfactory memory, but also involved in the integration of cognition and emotion in decision-making processes(17). Therefore, olfactory perception is considered to be integrated by the OFC with input from many cortical and subcortical areas responsible for basic sensory processing, as well as integrated with cognition apart from sensory input alone. Previous meta-analysis research based on voxel-coordinate mapping localized the regions of the OFC that respond to olfactory stimuli bilaterally near the orbital transverse sulci $(18$, 19). More recently, further study has established that damage in these regions may lead to a loss of the ability to consciously perceive odours, although the early sensory pathways are intact(20).

Olfactory afferents, especially from olfactory tracts, not only connect with the olfactory cortex but also interact with the limbic system (including the amygdala, hippocampus, lateral hypothalamus, and parahippocampal gyrus) to form memory and learning mechanisms(21). This study also found significant alterations in olfactory cortex $\mathrm{FC}$ common to both the KS and $\mathrm{nlHH}$ groups in the left inferior parietal lobule, middle temporal gyrus, angular gyrus, bilateral DLPFC, precentral gyrus, right supramarginal gyrus, inferior parietal lobule and postcentral gyrus; this finding suggests that these regions may represent shared neural pathways for psychopathophysiology.

The KS and $\mathrm{nIHH}$ groups showed a significantly different degree of damage and more alterations in olfactory cortex FC in $\mathrm{nIHH}$ patients than in KS patients when compared to HCs. We indicate that abnormalities in brain connectivity may be more significant in the neuropathophysiology of KS than that of $\mathrm{nIHH}$, which may lead to different clinical manifestations. In addition, a variety of specific neurologic disorders have been illustrated in KS $(22,23)$. These findings suggest that shared functional connectivity abnormalities across $\mathrm{KS}$ and $\mathrm{nIHH}$ patients may provide new clues to reveal the underlying pathophysiological mechanisms in these disorders. A growing number of reports have found that 
olfactory disorders are associated with cognitive function (24-27), which has been identified as an extensive structural or functional abnormality in the brain.

In this study, a decreased FA value of the UF was detected in KS patients. The UF connects the anterior part of the temporal lobes and the inferior frontal lobes (via the olfactory pathway) (28). It is the major fibre tract originating from the temporal lobe lateral to the amygdala and hippocampus, passes through the temporal stem and has a characteristic hooked shape as it curves upward into the extreme and external capsule to continue into the orbital gyrus $(29,30)$. The UF has a suggested decision-making role that is mediated by dopaminergic mechanisms(31,32). Disrupted UF connectivity may represent abnormal fronto-temporal white matter integrity via the olfactory pathway. DTI has been used to investigate KS patients in a few studies, and the reduced FA value in brain regions that correspond to the olfactory system has been revealed (33).

The most attractive findings in this study were the unilateral disruption of rsFC in the right olfactory cortex-prefrontal cortex and decreased FA of UF, which linked the two regions within the KS group. The results provide critical evidence that reveal the disruption of structural-functional connectivity in the right fronto-limbic system unilaterally, which complements and extends previous data implicating these areas in olfactory processing (34). We suggest a structural and functional specialization of the right frontolimbic system, also consistent with earlier behavioural findings $(35,36)$. Note also that this asymmetry occurs in the secondary olfactory cortex. This asymmetry may be a common feature of the organization of lateral-asymmetric perceptual systems, suggesting that hemispheric specialization is generally associated with higher-order processes rather than initial sensory analysis(37).

We inferred a negative correlation between the structural and functional connectivity in the right olfactory pathway. The mechanisms of the anatomical-functional relationship in the olfactory neural system have remained vague until now. It has been reported that structural abnormalities might disrupt the corresponding functional connectivity in the neural system. The negative correlation between structural and functional connectivity may reflect a compensatory mechanism; in the $\mathrm{HC}$ and $\mathrm{nlHH}$ groups, enhanced functional connectivity may have complemented lower structural connectivity to maintain the balance of olfactory pathways (fronto-limbic system). The compensatory mechanism may have been destroyed in the KS group, leading to an imbalanced pathway. This finding provides primary evidence that damaged structural-functional relationships may play an essential role in the neuropathophysiology of KS.

This study has some limitations. First, as a rare disease, the sample size is relatively small, so the results should be interpreted cautiously, and a study with a larger sample should be performed to investigate the olfactory pathway further. Second, our seed ROI was selected from an open-access anatomical atlas without detailed subregions. However, our selection was in accordance with previous reports that statistically localized the human olfactory cortex. Reproducibility and standardization in our study protocol still made some sense. Third, we only collected data on structural and functional connectivity, 
and we did not obtain volume data. This is an aspect worth investigating, and we will collect volume data in the future (via the voxel-based morphometry method).

\section{Conclusion}

In conclusion, we implicate the involvement of a multi-regional model of cerebral cortex integration in olfactory function development and pathophysiology. These findings suggest that shared functional connectivity abnormalities across KS and nIHH patients may provide new clues to reveal the underlying pathophysiological mechanisms in these disorders. We have reported significant structural-functional disruption unilaterally at the right junction of the fronto-limbic system in KS patients in the present study. The results may indicate that a specific structural-functional asymmetry exists in the olfactory cortex pathways in KS patients.

\section{Abbreviations}

AAL: Automated anatomical labelling; BOLD: Blood Oxygen Level-Dependent ; DLPFC: Dorsolateral prefrontal cortex; DTI: Diffusion Tensor Imaging; FA: Fractional Anisotropy; fMRI: functional Magnetic Resonance Imaging; FSH: Follicle-Stimulating Hormone ; GnRH: Gonadotropin-releasing Hormone; GRF: Gaussian Random Field; HCs: Healthy Controls; IHH: Idiopathic Hypogonadotropic Hypogonadism; KS: Kallmann's Syndrome; LH: Luteinizing hHormone; MNI: Montreal Neurological Institute; nIHH: normosmic Idiopathic Hypogonadotropic Hypogonadism; OFC: Orbitofrontal cortex; ROIs: Regions of Interest; rsFC: resting-state Functional Connectivity; UF: Uncinate Fasciculus.

\section{Declarations}

\section{Ethics Approval and Consent to participate}

All procedures performed in studies involving human participants were in accordance with the ethical standards of the institutional and/or national research committee and with the 1964 Helsinki Declaration and its later amendments or comparable ethical standards. Informed consent was obtained from all individual participants included in the study.

\section{Consent for publication}

Not applicable.

\section{Availability of data and material:}

The datasets generated during and/or analyzed during the current study are available from the corresponding author on reasonable request. 


\section{Competing interests:}

The authors declare that they have no competing interests.

\section{Funding:}

This research did not receive any specific grant from funding agencies in the public, commercial, or notfor-profit sectors.

\section{Authors' contributions:}

JC and LC drafted initial analyses, wrote, and edited the manuscript. ZY,BC and HL were responsible for examination, data collecting and assembling. MC was responsible for clinical information gathering, statistic analysis.CL supervised the data analysis and reviewed the manuscript. GF conceptualized the study design, was responsible for reviewed, and edited the manuscript. All the authors contributed to manuscript revision, read and approved the final version.

\section{Acknowledgements】}

Not applicable.

\section{References}

1. Sykiotis GP, Plummer L, Hughes VA, Au M, Durrani S, Nayak-Young S, et al. Oligogenic basis of isolated gonadotropin-releasing hormone deficiency. Proceedings of the National Academy of Sciences of the United States of America. 2010;107(34):15140-

4.https://doi.10.1073/pnas.1009622107.

2. Schwanzel-Fukuda M, Pfaff DW. Origin of luteinizing hormone releasing hormone neurons. Nature. 1989;338(6211):161-4.https://doi.10.1038/338161a0.

3. Stopa EG, Koh ET, Svendsen CN, Rogers WT, Schwaber JS, King JC. Computer-assisted mapping of immunoreactive mammalian gonadotropin-releasing hormone in adult human basal forebrain and amygdala. Endocrinology. 1991;128(6):3199 - 207.https://doi.10.1210/endo-128-6-3199.

4. Schwanzel-Fukuda M, Bick D, Pfaff DW. Luteinizing hormone-releasing hormone (LHRH)-expressing cells do not migrate normally in an inherited hypogonadal (Kallmann) syndrome. Brain Res Mol Brain Res. 1989;6(4):311 - 26.

5. Rugarli El, Lutz B, Kuratani SC, Wawersik S, Borsani G, Ballabio A, et al. Expression pattern of the Kallmann syndrome gene in the olfactory system suggests a role in neuronal targeting. Nat Genet. 1993;4(1):19-26.https://doi.10.1038/ng0593-19. 
6. Thomann PA, Dos Santos V, Toro P, Schonknecht P, Essig M, Schroder J. Reduced olfactory bulb and tract volume in early Alzheimer's disease-a MRI study. Neurobiol Aging. 2009;30(5):838 41.https://doi.10.1016/j.neurobiolaging.2007.08.001.

7. Schneider JF, Floemer F. Maturation of the olfactory bulbs: MR imaging findings. AJNR Am J Neuroradiol. 2009;30(6):1149-52.https://doi.10.3174/ajnr.A1501.

8. Bauknecht HC, Jach C, Fleiner F, Sedlmaier B, Goktas O. [Olfactory dysfunction: correlation of olfactory bulb volume on MRI and objective olfactometry]. Rofo. 2010;182(2):1638.https://doi.10.1055/s-0028-1109816.

9. Manara R, Salvalaggio A, Favaro A, Palumbo V, Citton V, Elefante A, et al. Brain changes in Kallmann syndrome. AJNR Am J Neuroradiol. 2014;35(9):1700-6.https://doi.10.3174/ajnr.A3946.

10. Vogl TJ, Stemmler J, Heye B, Schopohl J, Danek A, Bergman C, et al. Kallman syndrome versus idiopathic hypogonadotropic hypogonadism at MR imaging. Radiology. 1994;191(1):53 7.https:// doi.10.1148/radiology.191.1.8134597.

11. Ward PGD, Orchard ER, Oldham S, Arnatkeviciute A, Sforazzini F, Fornito A, et al. Individual differences in haemoglobin concentration influence bold fMRI functional connectivity and its correlation with cognition. Neuroimage.

2020;221:117196.https://doi.10.1016/j.neuroimage.2020.117196.

12. Honey CJ, Sporns O, Cammoun L, Gigandet X, Thiran JP, Meuli R, et al. Predicting human restingstate functional connectivity from structural connectivity. Proceedings of the National Academy of Sciences of the United States of America. 2009;106(6):2035-

40.https://doi.10.1073/pnas.0811168106.

13. Wang Z, Dai Z, Gong G, Zhou C, He Y. Understanding structural-functional relationships in the human brain: a large-scale network perspective. The Neuroscientist: a review journal bringing neurobiology, neurology and psychiatry. 2015;21(3):290-305.https://doi.10.1177/1073858414537560.

14. Doty RL, Shaman P, Dann M. Development of the University of Pennsylvania Smell Identification Test: a standardized microencapsulated test of olfactory function. Physiol Behav. 1984;32(3):489502.

15. Tzourio-Mazoyer N, Landeau B, Papathanassiou D, Crivello F, Etard O, Delcroix N, et al. Automated anatomical labeling of activations in SPM using a macroscopic anatomical parcellation of the MNI MRI single-subject brain. Neurolmage. 2002;15(1):273 - 89.https://doi.10.1006/nimg.2001.0978.

16. Cui Z, Zhong S, Xu P, He Y, Gong G. PANDA: a pipeline toolbox for analyzing brain diffusion images. Frontiers in human neuroscience. 2013;7:42.https://doi.10.3389/fnhum.2013.00042.

17. Bechara A, Damasio H, Damasio AR. Emotion, decision making and the orbitofrontal cortex. Cereb Cortex. 2000;10(3):295-307. https://doi.10.1093/cercor/10.3.295.

18. Gottfried JA, Zald DH. On the scent of human olfactory orbitofrontal cortex: meta-analysis and comparison to non-human primates. Brain Res Brain Res Rev. 2005;50(2):287304.https://doi.10.1016/j.brainresrev.2005.08.004. 
19. Gottfried JA. What can an orbitofrontal cortex-endowed animal do with smells? Ann N Y Acad Sci. 2007;1121:102 - 20.https://doi.10.1196/annals.1401.018.

20. Silveira-Moriyama L, Azevedo AM, Ranvaud R, Barbosa ER, Doty RL, Lees AJ. Applying a new version of the Brazilian-Portuguese UPSIT smell test in Brazil. Arq Neuropsiquiatr. 2010;68(5):7005.https:// doi.10.1590/s0004-282x2010000500005.

21. Quinton R, Duke VM. de Zoysa PA, Platts AD, Valentine A, Kendall B, et al. The neuroradiology of Kallmann's syndrome: a genotypic and phenotypic analysis. J Clin Endocrinol Metab. 1996;81(8):3010-7.https://doi.10.1210/jcem.81.8.8768867.

22. Quinton R, Duke VM, Robertson A, Kirk JM, Matfin G. et al. Idiopathic gonadotrophin deficiency: genetic questions addressed through phenotypic characterization. Clin Endocrinol (Oxf). 2001;55(2):163 - 74., de Zoysa PA.

23. Danek A, Heye B, Schroedter R. Cortically evoked motor responses in patients with Xp22.3-linked Kallmann's syndrome and in female gene carriers. Ann Neurol. 1992;31(3):299304.https://doi.10.1002/ana.410310312.

24. Verhoeven WM, Egger JI, Hovens JE, Hoefsloot L. Kallmann syndrome and paranoid schizophrenia: a rare combination. BMJ Case Rep. 2013;2013.https://doi.10.1136/bcr-2012-007387.

25. Vagenakis GA, Hyphantis TN, Papageorgiou C, Protonatariou A, Sgourou A, Dimopoulos PA, et al. Kallmann's syndrome and schizophrenia. Int J Psychiatry Med. 2004;34(4):379 90.https://doi.10.2190/HXR5-DGRC-JCMQ-0CBH.

26. Cowen MA, Green M. IL-1b and Kallmann's syndrome: a variant model of schizophrenia? Biol Psychiatry. 1993;33(2):71 - 2.https://doi.10.1016/0006-3223(93)90304-v.

27. Lee YH, Bak Y, Park CH, Chung SJ, Yoo HS, Baik K, et al. Patterns of olfactory functional networks in Parkinson's disease dementia and Alzheimer's dementia. Neurobiol Aging.

2019.https://doi.10.1016/j.neurobiolaging.2019.12.021.

28. Rodrigo S, Oppenheim C, Chassoux F, Golestani N, Cointepas Y, Poupon C, et al. Uncinate fasciculus fiber tracking in mesial temporal lobe epilepsy. Initial findings. European radiology. 2007;17(7):16638.https://doi.10.1007/s00330-006-0558-x.

29. Kier EL, Staib LH, Davis LM, Bronen RA. MR imaging of the temporal stem: anatomic dissection tractography of the uncinate fasciculus, inferior occipitofrontal fasciculus, and Meyer's loop of the optic radiation. AJNR Am J Neuroradiol. 2004;25(5):677 - 91.

30. Fan LY, Lai YM, Chen TF, Hsu YC, Chen PY, Huang KZ, et al. Diminution of context association memory structure in subjects with subjective cognitive decline. Hum Brain Mapp. 2018;39(6):254962.https://doi.10.1002/hbm.24022.

31. Bolhuis K, Muetzel RL, Stringaris A, Hudziak JJ, Jaddoe VWV, Hillegers MHJ, et al. Structural Brain Connectivity in Childhood Disruptive Behavior Problems: A Multidimensional Approach. Biol Psychiatry. 2019;85(4):336 - 44.https://doi.10.1016/j.biopsych.2018.07.005.

32. Olson IR. Von Der Heide RJ, Alm KH, Vyas G. Development of the uncinate fasciculus: Implications for theory and developmental disorders. Dev Cogn Neurosci. 2015;14:50- 
61.https://doi.10.1016/j.dcn.2015.06.003.

33. Garcia-Gonzalez D, Murcia-Belmonte V, Clemente D. De Castro F. Olfactory system and demyelination. Anat Rec (Hoboken). 2013;296(9):1424-34.https://doi.10.1002/ar.22736.

34. Yao L, Pinto JM, Yi X, Li L, Peng P, Wei Y. Gray matter volume reduction of olfactory cortices in patients with idiopathic olfactory loss. Chem Senses. 2014;39(9):755 60.https://doi.10.1093/chemse/bju047.

35. Yao LY, Guo YC, Zhan XJ, Sun ZF, Li Y, Wei YX. [Preliminary study of DTI on cerebral white matter micro-structure of patients with idiopathic olfactory loss]. Lin Chung Er Bi Yan Hou Tou Jing Wai Ke Za Zhi. 2018;32(6):435-8.https://doi.10.13201/j.issn.1001-1781.2018.06.009.

36. Zatorre RJ, Jones-Gotman M, Evans AC, Meyer E. Functional localization and lateralization of human olfactory cortex. Nature. 1992;360(6402):339 - 40.https://doi.10.1038/360339a0.

37. Villafuerte G, Miguel-Puga A, Arias-Carrion O. Continuous Theta Burst Stimulation Over the Right Orbitofrontal Cortex Impairs Conscious Olfactory Perception. Front Neurosci. 2019;13:555.https://doi.10.3389/fnins.2019.00555.

\section{Tables}

Table I: Main clinical and demographic features in IHH patients

Note: $\mathrm{HH}$ : hypogonadotropic hypogonadism; rOB, right olfactory bulb; IOB, left olfactory bulb; bOB, bilateral olfactory bulbs.

Table II. Anatomical location of areas of showing significant Olfactory cortex-FC differences between groups. 


\begin{tabular}{|c|c|c|c|c|c|c|}
\hline $\begin{array}{l}\text { Subjects } \\
\text { NO. }\end{array}$ & Age & $\mathrm{HH}$ & Olfactory®Function & Handedness & $\begin{array}{l}\text { MRI } \\
\text { Abnormalities }\end{array}$ & $\begin{array}{l}\text { Clinical } \\
\text { diagnosis }\end{array}$ \\
\hline 1 & 19 & YES & Normal & Right & Normal & $\mathrm{nlHH}$ \\
\hline 2 & 18 & YES & Anosmia & Right & $\begin{array}{l}\text { bOB } \\
\text { hypoplasia }\end{array}$ & KS \\
\hline 3 & 20 & YES & Normal & Right & Normal & $\mathrm{nlHH}$ \\
\hline 4 & 17 & YES & Normal & Right & Normal & $\mathrm{nlHH}$ \\
\hline 5 & 19 & YES & Anosmia & Right & $\begin{array}{l}\text { bOB } \\
\text { hypoplasia }\end{array}$ & KS \\
\hline 6 & 19 & YES & hyposmia & Right & rOB hypoplasia & KS \\
\hline 7 & 16 & YES & Anosmia & Left & $\begin{array}{l}\text { bOB } \\
\text { hypoplasia }\end{array}$ & KS \\
\hline 8 & 21 & YES & Normal & Right & Normal & $\mathrm{nlHH}$ \\
\hline 9 & 17 & YES & Normal & Right & Normal & $\mathrm{nlHH}$ \\
\hline 10 & 16 & YES & Anosmia & Right & bOB aplasia & KS \\
\hline 11 & 19 & YES & Normal & Right & Normal & $\mathrm{nlHH}$ \\
\hline 12 & 18 & YES & Normal & Right & Normal & $\mathrm{nlHH}$ \\
\hline 13 & 21 & YES & Normal & Right & Normal & $\mathrm{nlHH}$ \\
\hline 14 & 16 & YES & Normal & Right & Normal & $\mathrm{nIHH}$ \\
\hline 15 & 17 & YES & hyposmia & Left & $\begin{array}{l}\text { bOB } \\
\text { hypoplasia }\end{array}$ & KS \\
\hline 16 & 18 & YES & Anosmia & Right & bOB aplasia & $\mathrm{KS}$ \\
\hline 17 & 17 & YES & Anosmia & Right & $\begin{array}{l}\text { bOB } \\
\text { hypoplasia }\end{array}$ & KS \\
\hline 18 & 18 & YES & hyposmia & Right & IOB hypoplasia & KS \\
\hline 19 & 19 & YES & Anosmia & Right & $\begin{array}{l}\text { bOB } \\
\text { hypoplasia }\end{array}$ & KS \\
\hline 20 & 18 & YES & Normal & Right & Normal & $\mathrm{nlHH}$ \\
\hline 21 & 18 & YES & Anosmia & Right & $\begin{array}{l}\text { bOB } \\
\text { hypoplasia }\end{array}$ & KS \\
\hline 22 & 15 & YES & Normal & Right & Normal & $\mathrm{nlHH}$ \\
\hline 23 & 18 & YES & Normal & Right & Normal & $\mathrm{nlHH}$ \\
\hline 24 & 16 & YES & Normal & Right & Normal & $\mathrm{nIHH}$ \\
\hline
\end{tabular}




\section{Peak MNI}

Coordinates

Brain area

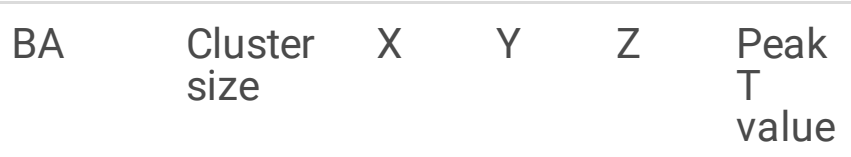

KS vs. HC

Left gyrus rectus/Left orbitofrontal cortex

11

63

$\begin{array}{lll}-6 & 33 & -21\end{array}$

$-3.34$

Left gyrus rectus/Left orbitofrontal cortex

11

98

27

42

$-21$

$-4.36$

Left middle temporal gyrus/Left angular gyrus

39

41

$\begin{array}{lll}-54 & -66 & 27\end{array}$

$-3.34$

Right supramarginal gyrus/ Right postcentral gyrus

40

249

$\begin{array}{lll}54 & -42 & 57\end{array}$

$-5.93$

Left precentral gyrus/Left dorsolateral prefrontal cortex

Left inferior parietal lobule

$\begin{array}{llllll}6 / 9 & 120 & -45 & 9 & 30 & -3.66\end{array}$

Bilateral dorsolateral prefrontal cortex

$\begin{array}{llllll}40 & 338 & -30 & -60 & 39 & -4.74 \\ 6 / 8 & 764 & 21 & 36 & 57 & -4.41\end{array}$

nIHH vs. HC

Bilateral gyri recti/Bilateral orbitofrontal cortex

11

Left middle temporal gyrus

39

Left supramarginal gyrus/ Left angular gyrus

$39 / 40 \quad 50$

Bilateral dorsolateral prefrontal cortex

$6 / 8 \quad 308$

Left inferior parietal lobule

40

Right dorsolateral prefrontal cortex

$8 / 9$

24

19

Left precuneus/ Left angular gyrus

Left precentral gyrus/ Left postcentral gyrus

Left precentral gyrus / Left dorsolateral prefrontal cortex

6

$19-2$

Left inferior parietal lobule

Right postcentral gyrus

$\begin{array}{lllll}3 & 48 & -36 & 63 & -5.99\end{array}$

KS vs. $\mathrm{nIHH}$

Left orbitofrontal cortex

Right gyrus rectus/ Right orbitofrontal cortex
11

11
442

2

2

10

$-5$

$\begin{array}{lll}-24 & -12 & 57\end{array}$

57

$-2.85$

$\begin{array}{lll}48 & 18 & 51\end{array}$

$-4.90$

$\begin{array}{llll}-36 & -72 & 42 & -2.78\end{array}$

$\begin{array}{lll}-57 & -6 & 48\end{array}$

6.48

$\begin{array}{llll}-42 & 18 & 51 & -4.99\end{array}$

$\begin{array}{lll}-48 & -30 & 39\end{array}$

$-3.13$ 
Right supramarginal gyrus

Left precentral gyrus/ Left postcentral gyrus/ Left inferior parietal lobule

Left dorsolateral prefrontal cortex

Right postcentral gyrus

Right dorsolateral prefrontal cortex
10

9

8

19

2

6

9
51

$-33$

27

$-4.76$

$\begin{array}{llll}-30 & -39 & 51 & -3.70\end{array}$

$-42$

$\begin{array}{lll}48 & -33 & 63\end{array}$

$21 \quad-6 \quad 75$
4.45

3.96

4.62

Note: These findings correspond to a corrected $P<.05$ by GRF correction. BA Brodmann's area. Cluster size is in $\mathrm{mm}^{3}$

\section{Figures}
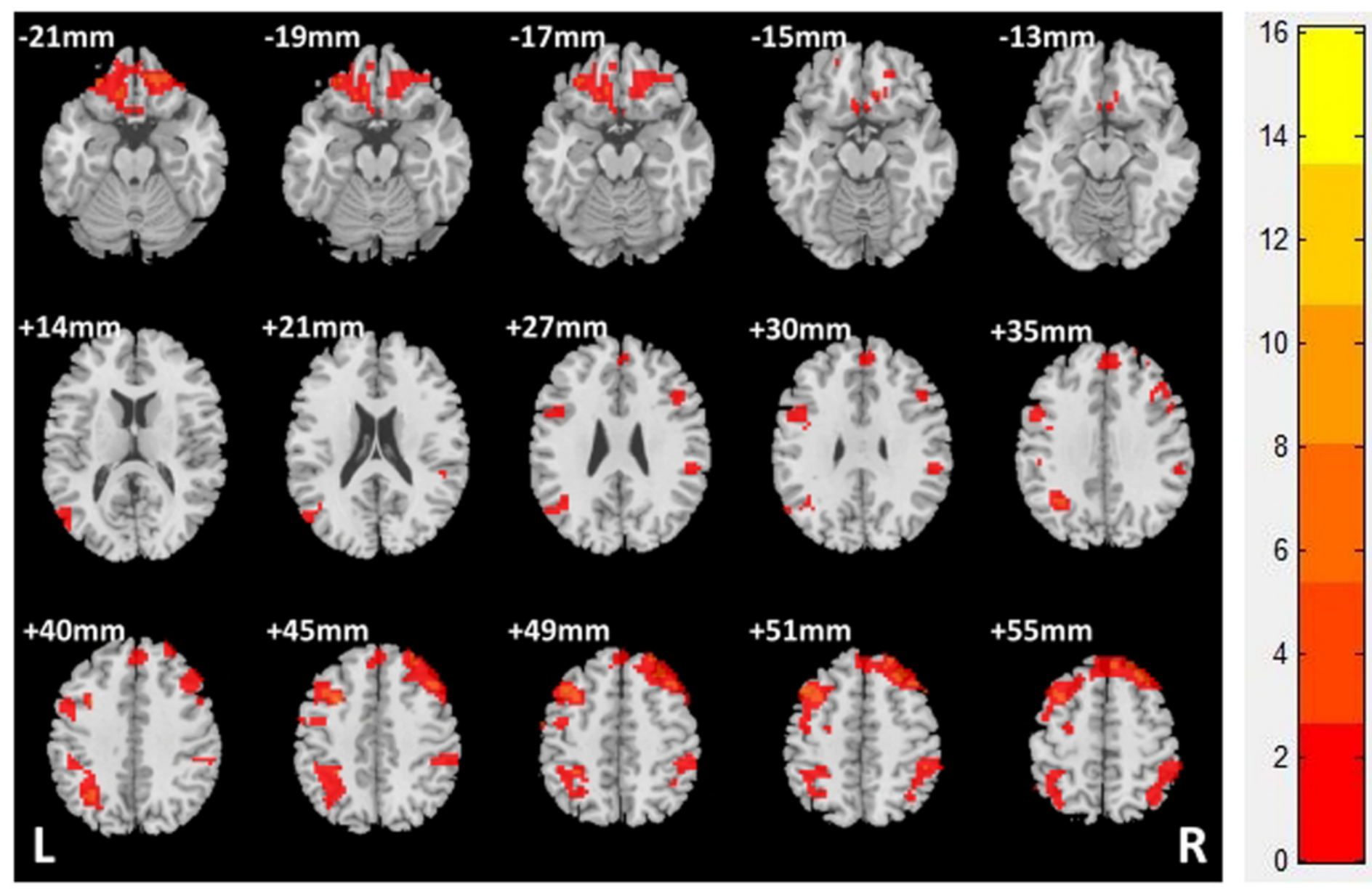

\section{Figure 1}

Functional connectivity (FC) result maps of the comparison among three groups. The axial images show the regions in the bilateral gyri recti, orbitofrontal cortex(OFC) dorsolateral prefrontal cortex(DLPFC), inferior parietal lobule, left middle temporal gyrus, angular gyrus, precentral gyrus, right supramarginal 
gyrus and postcentral gyrus. These regions show a significant difference with bilateral olfactory cortexassociated functional connectivity among three groups. The findings are displayed on a T1 image. ${ }^{*} \mathrm{P}$ 0.05. The color bar represents the range of $F$ values.
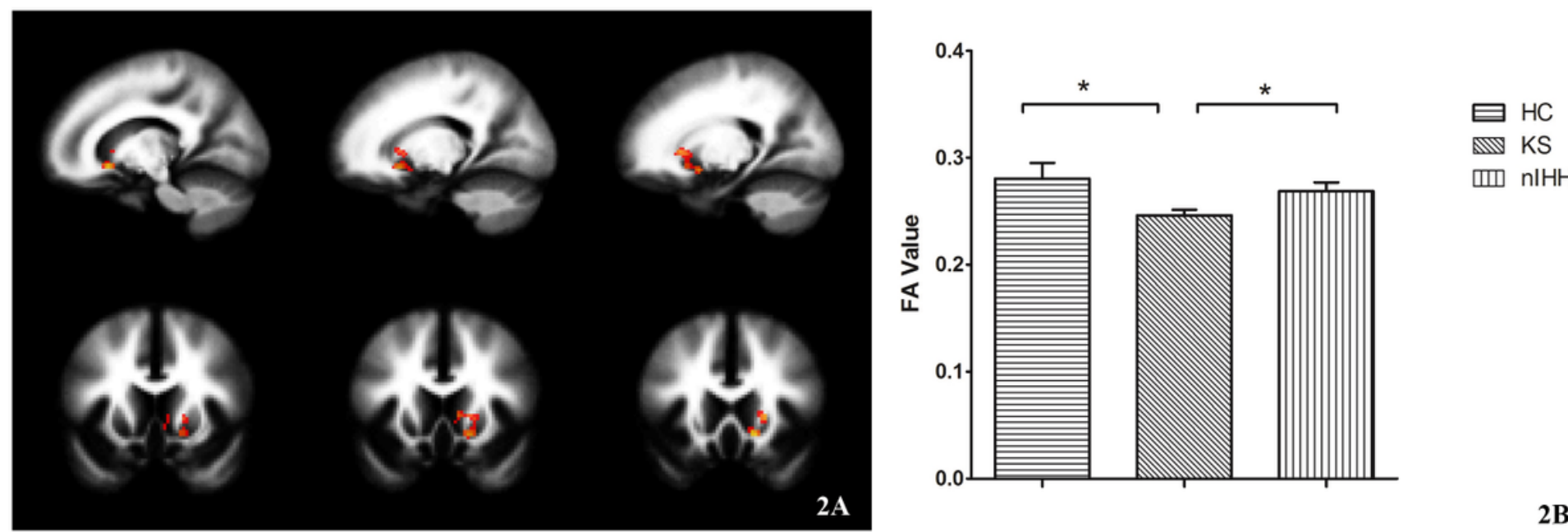

Figure 2

Maps of the FA results of the comparison among three groups. (2A) The images show that the FA value in the right uncinate fasciculus (UF) decreased significantly in the KS group compared with the $\mathrm{HC}$ and $\mathrm{nlHH}$ groups. The findings are displayed on a tissue probability map of white matter. (2B) The graph shows the mean FA value and standard errors in the right UF for the three groups. ${ }^{*} \mathrm{P}<0.05$.

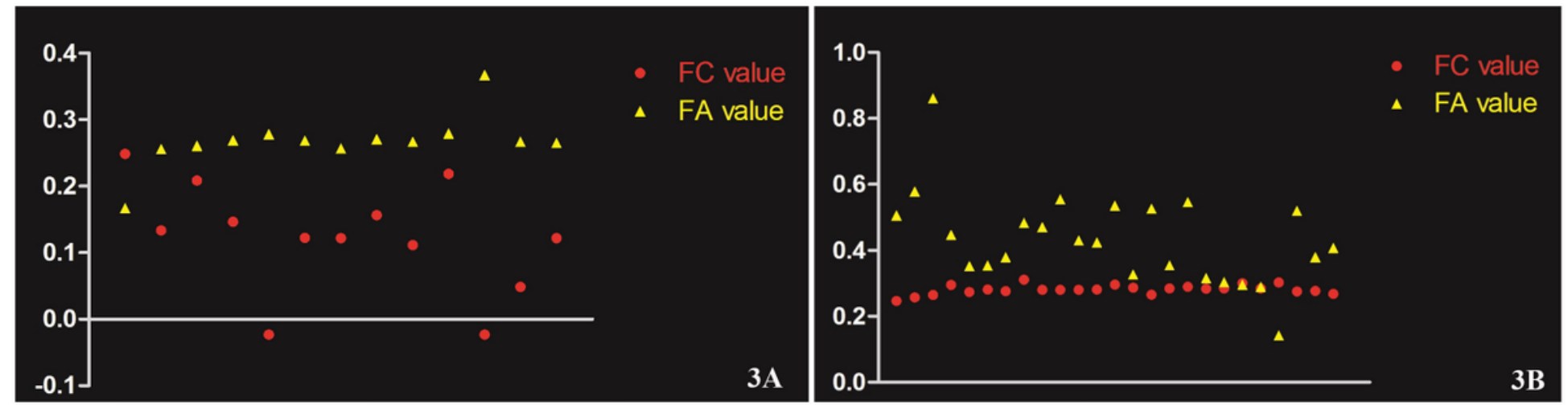

\section{Figure 3}

The correlations between the FA value and the strength of the FC. There were significant negative correlations between right UF FA values and olfactory cortex $\mathrm{FC}$ to both the gyrus rectus and OFC within the $\mathrm{nIHH}(3 \mathrm{~A})(r=-0.437 ; \mathrm{P}=0.03)$ and $\mathrm{HC}$ groups $(3 \mathrm{~B})(r=-0.682 ; P=0.01)$.

\section{Supplementary Files}

This is a list of supplementary files associated with this preprint. Click to download.

- figS1.tif 
- figS2Akshc.tif

- figS2Bksihh.tif

- figS2Chcihh.tif 